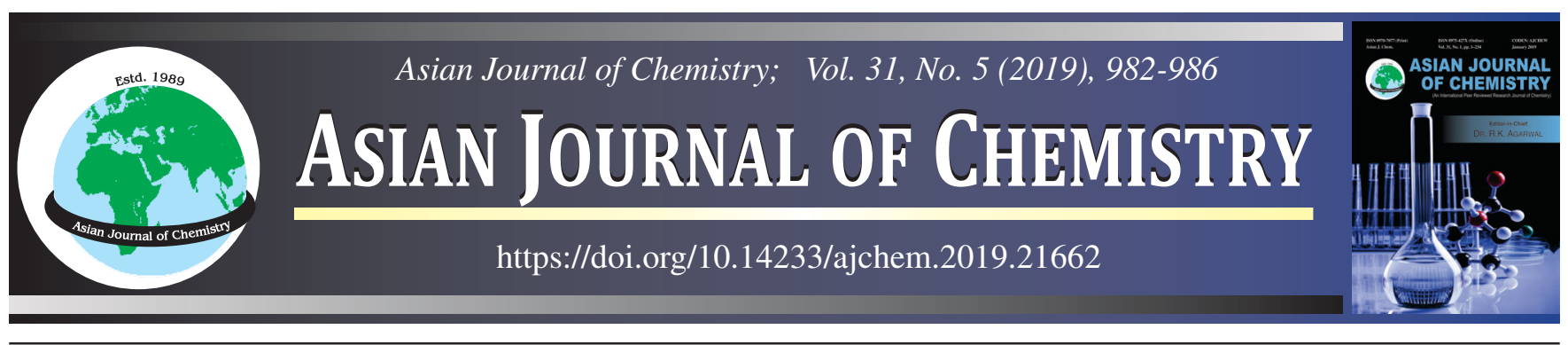

\title{
ab initio Method on the Mechanism of Acetalization of 2-Methoxybenzaldehyde Using Halogen Acid Catalysts
}

\author{
Muhammad YusuF ${ }^{*}$, Dahniar, Destria Roza and Marini Damanik
}

Department of Chemistry, Universitas Negeri Medan, Jl. Willem Iskander Psr V Medan, 20221, Indonesia

*Corresponding author: Fax: +62 61 6614002/6613319; Tel.: +62 61 6613365; E-mail: yusuf.6423@ gmail.com

ab initio method used on the mechanism of acetalization of 2-methoxybenzaldehyde. ab initio method is a quantum mechanical approximate calculation and derived directly only from theoretical principles. All geometry optimizations were performed using 3-21G and 6-31G* basis set with Hyperchem 8.0 software (windows version). The aim of this study was to focus on the study of the mechanism of acetalization of 2-methoxybenzaldehyde using hydrochloric acid as catalysts. The computational calculation not only provided possible reaction steps but also provided possible energy change in each step of the reaction mechanism of acetalization of 2-methoxybenzaldehyde. The result showed that 2-methoxybenzaldehyde $(0 \mathrm{~kJ} / \mathrm{mol})$ has the lowest energy and electronegativity compared to acetal product $(-17.43 \mathrm{~kJ} / \mathrm{mol})$ and a labile hemiacetal $(448.33 \mathrm{~kJ} / \mathrm{mol})$ due to its stability and the influence of neighbour atom.

| Keywords: ab initio method, Acetalization, 2-Methhoxybenzaldehyde, Halogen catalyst.

ᄂ - - - - - - - - - - - - - - - - - - - - - - - - - - - - -

\section{INTRODUCTION}

In the recent year, acetals have been widely applied in the solvents, foods and beverages as an additive, fragrances in cosmetics, pharmaceuticals, drugs design, detergents, lacquer industries, carbohydrates and intermediates or final products in petrochemicals and fine chemicals processes. Additionally, acetals also used in acetalization reaction to protect carbonyl compounds [1].

Acetals were usually synthesized from carbonyl compounds such as benzaldehyde with an alcohol that catalyzed by an acid catalyst as shown in Scheme-I [2]. So far, a few catalysts such as MCM-41 [3], indium triflate [4] and NCS/ thiourea [5], $\mathrm{H}_{4}\left[\mathrm{SiW}_{12} \mathrm{O}_{40}\right] / \mathrm{SiO}_{2}$ [6], mesoporous metal-organic framework MIL-100(Fe) [7], aluminium and thiourea containing MOF [8,9], MOF MIL-101 bearing sulfonic acid groups [10], metal-organic frameworks (MOFs) based on the UiO66(Zr) structure [11], copper, iron, zeolite beta [12], benzimidazolium cation [13] and UIO 66 catalyst [14] have a function as catalyst in the acetalization of benzaldehyde.

The mechanism of acetal formation is carried out by replacing an -OH group with an OR' group. This formation is mostly similar to an $\mathrm{SN}^{1}$ mechanism. Generally, acetals can

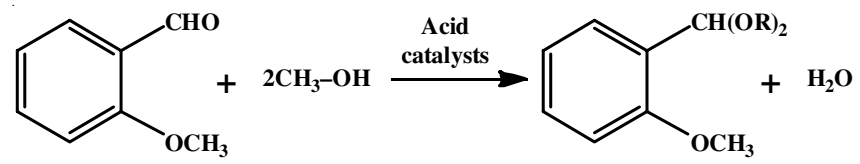

Scheme-I: Acetalization of 2-methoxybenzaldehyde using acid catalysts [Ref. 15]

be synthesized using acid catalysts and via a two-steps process. The first step was formation of hemiacetal by reacted benzaldehyde substrate with an alcohol followed with protonation of benzaldehyde by an acid catalyst, nucleophilic attack by a methanol and deprotonation to form a hemiacetal. The formation of hemiacetal also named as halfway processing to form acetals. The second step produced acetal by reaction of hemiacetal with second alcohol molecule followed with protonation of hemiacetal by an acid catalyst, removal of water, nucleophilic attack by a methanol and the last was the loss of water to form acetal product $[2,15,16]$. Yusuf et al. $[16,17]$ reported the reaction mechanism of acetalization of benzaldehyde and 2-hydroxy benzaldehyde used acid catalysts $(\mathrm{HCl})$ and applied with Hyperchem software. The reaction results is an acetal product with an $\mathrm{SN}^{1}$ mechanism. Based on the computational calculation, hemiacetal had a higher energy compared to

This is an open access journal, and articles are distributed under the terms of the Creative Commons Attribution-NonCommercial-ShareAlike 4.0 (CC BY-NC-SA 4.0) International License which allows readers to freely read, download, copy, distribute, print, search, or link to the full texts of its articles and to use them for any other lawful non-commercial purpose as long as the original source is duly acknowledged. 
benzaldehyde substrate and acetal product. In overall, the reaction mechanism occurs via a reversible reaction.

In this work, we reported ab initio calculations of the reaction mechanism of acetalization of 2-methoxybenzaldehyde using halogen acid catalyst. ab initio is the method that only derived directly from theoretical principles without a presence of experimental data. Because of that $a b$ initio called "from the beginning". In addition, we also reported an energy changes and Mulliken charge of atom in every step of the reaction.

\section{EXPERIMENTAL}

To obtain the minimum energy obtained from all structures such as reactants, intermediates and products in acetalization of benzaldehyde, which carried out from geometry optimization. Besides that, the addition of free positive $\mathrm{H}$-ion is done when the computational calculation applied to obtain the minimum energy of hemiacetal and acetal product.

ab initio method with 6-31G* basis sets used to optimized the structures. Whereas, ab initio method with $3-21 \mathrm{G}$ basis sets used as a comparison. To operate and to visualize geometry structure were performed using Hyperchem 8.0 program (Windows version) [18]. As a result, the geometry structure optimization had the most stable molecule structure based on its lowest energy. Furthermore, the lowest energy represented by $\Delta \mathrm{E}$ which, obtained the energy change in every step of reaction process including reactant, intermediates and product. The energies are given in $\mathrm{kJ} / \mathrm{mol}$ and unscaled. The energy change of each stage of the reaction is defined as follows:

$$
\Delta \mathrm{E}=\Delta \mathrm{E}_{\text {products }}-\Delta \mathrm{E}_{\text {Reactant }}
$$

\section{RESULTS AND DISCUSSION}

$a b$ initio method has used to identify the reaction mechanism of the acetalization of 2-methoxybenzaldehyde and also can be carried out to identification possible reaction steps. The computational calculation resulted in the energy changes and the lowest energy in every step of the reaction. The reaction mechanism of acetalization of 2-methoxybenzaldehyde produce acetalas shown in Scheme-I.

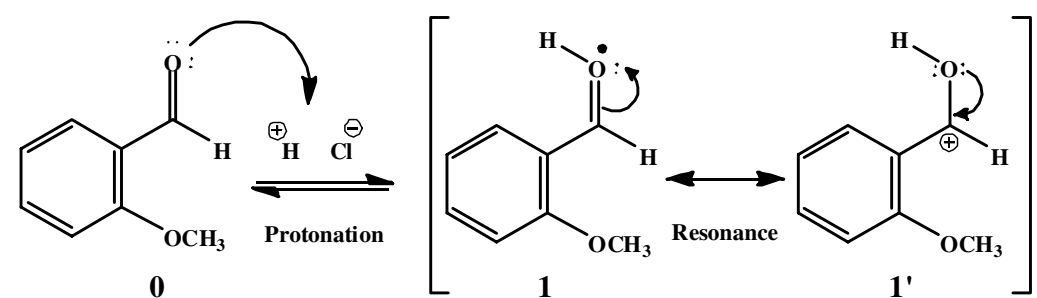

2-Methoxy benzaldehyde<smiles>COc1ccccc1C([AlH])([Hg])O[Mg]</smiles><smiles>COc1cccc(OC)c1OC</smiles>
$\mathbf{2}^{\prime}$<smiles>COc1ccccc1C(O)(O)OC</smiles>
3<smiles>CO[C@H]1C[C@@H](I)[C@H]1C</smiles><smiles>CO[Hg]C1CCCOc2ccccc21</smiles><smiles>C=[Tl]</smiles>

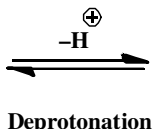<smiles>COc1ccccc1C(O)(O)C(C)O</smiles>

2

Hemiacetal

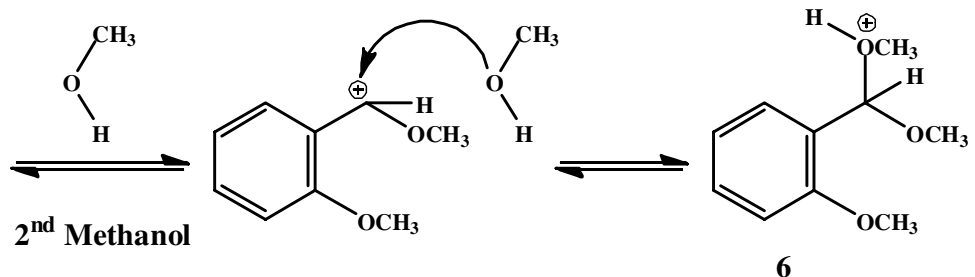<smiles>C=CC(C=C)C=C</smiles><smiles>COc1ccccc1C(C)(O)OC</smiles>

Acetal 7

Scheme-II: Reaction mechanism of acetalization of 2-methoxybenzaldehyde to produce acetal 
Reaction mechanism: There is a two-step process to produce acetal product. The first is the formation of a hemiacetal (3). The mechanism is started from protonation of carbonyl by the $\mathrm{Br} \varnothing n$ sted acid $\left(\mathrm{H}^{+}\right.$ions of the acid catalyst) because there is a weak nucleophile in benzaldehyde compound and produce compound 1. After protonation $\mathrm{C} 7-\mathrm{O} 9$ bond is elongated from 1.18 to $1.27 \AA$ A because of the influence of O9 neighbour atom which has bonded with $\mathrm{H} 10$ atom. O9-H10 bond became hydroxyl group and including a good leaving group as shown in Scheme-II.
Computational calculation carried out by using ab initio method with $6-31 \mathrm{G}^{*}$ basis sets. Compound $\mathbf{1}$ also has another resonance structure that is compound $\mathbf{1}^{\prime}$ which has similar C7-O9 bond distance that is $1.27 \AA$. Compound $\mathbf{1}$ as well as $\mathbf{1}$ ' has the similar energy too that is $472.90 \mathrm{~kJ} / \mathrm{mol}$ as shown in Fig. 1. This is proof that compound $\mathbf{1}$ and $\mathbf{1}$ ' is resonance structure. To give space for first methanol attack the resonance structure, the bond angle of $\mathrm{O} 9-\mathrm{C} 7-\mathrm{C} 3$ detected in $125^{\circ}$, whereas the torsion angle $\mathrm{O} 9-\mathrm{C} 7-\mathrm{H} 8-\mathrm{C} 3$ is $179^{\circ}$.
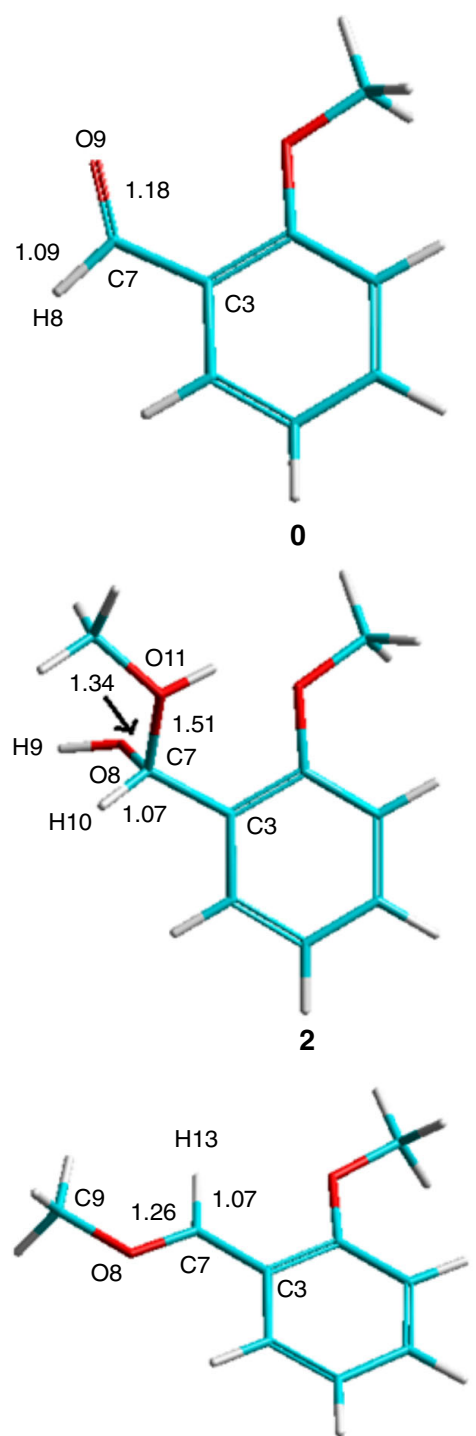

5
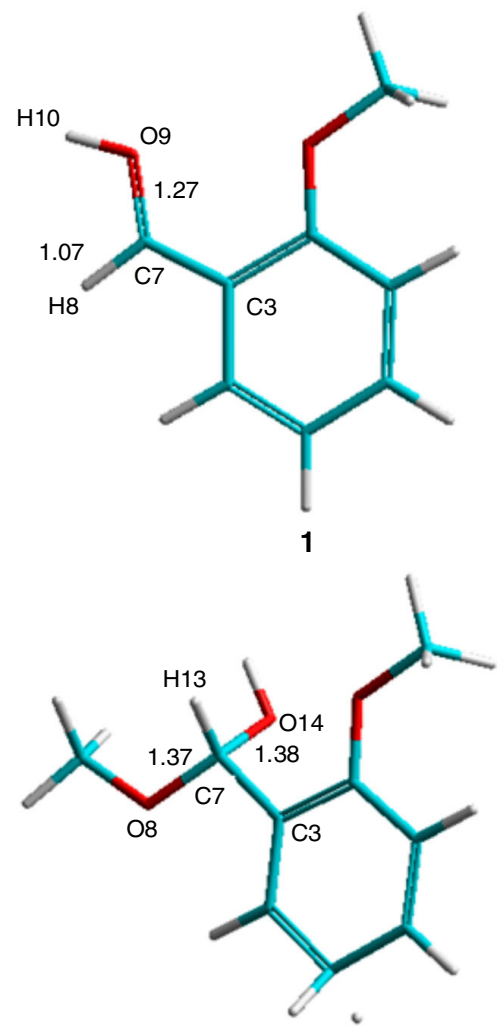

3
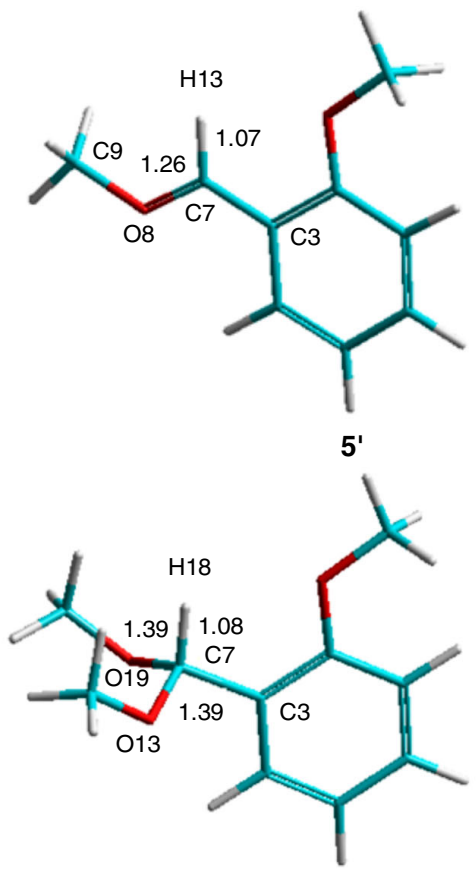
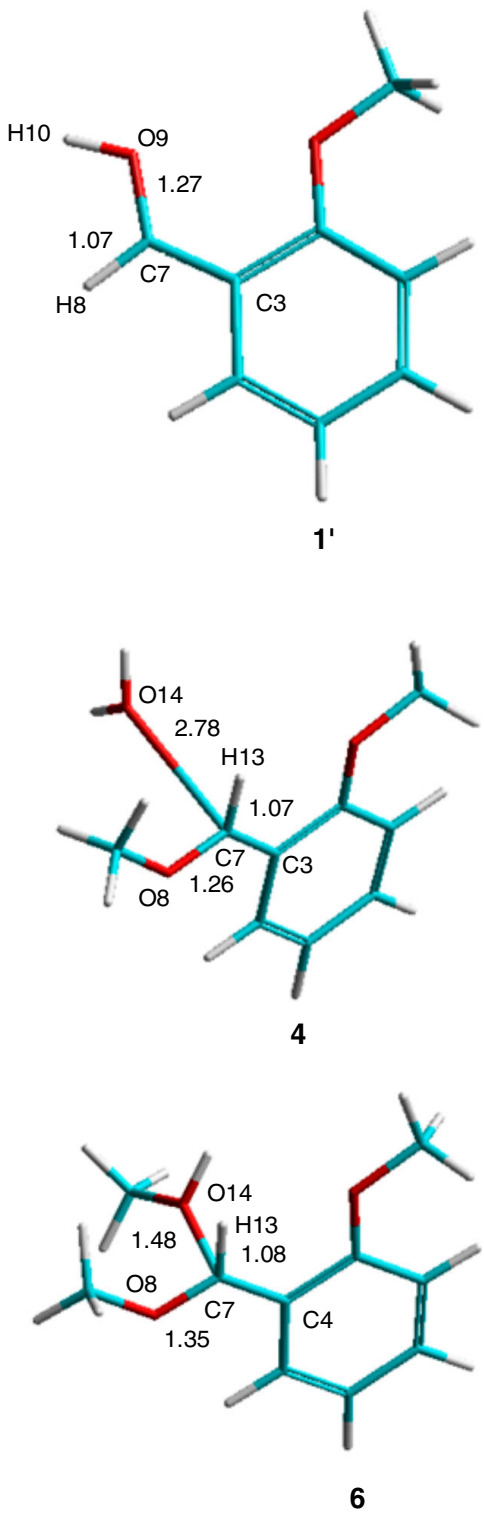

7

Fig. 1. Optimized geometries of intermediates during acetalization of 2-methoxybenzaldehyde 
The bond distance C7-O11 atom that has been newly created is $1.51 \AA$. Whereas $\mathrm{C} 7-\mathrm{O} 8$ elongated from 1.27 to 1.34 $\AA$ because there is an influence of $\mathrm{O} 11$ neighbor atom, which has bonded with a $\mathrm{C} 7$ atom. After that, alcoholic oxonium ion lost a proton become hemiacetal (3). Bond distance C7-O8 reduced from 1.51 to $1.38 \AA$. Besides that hemiacetal is a neutral molecule. As a result, the formation energy of hemiacetals decreased from 465.08 to $448.33 \mathrm{~kJ} / \mathrm{mol}$. Because of that, hemiacetal (3) is more stable than compound 2, $\mathbf{1}$ and $\mathbf{1}$ ' based on the energy of the molecule. The formation of hemiacetal determined to rate the step in acetalization of 2-methoxy benzaldehyde. Hemiacetals are unstable compared to benzaldehyde substrate and acetal product. Hemiacetals have no carbonyl functional groups.

The second was formation of an acetal product (7) [16]. The mechanism started from protonation that initiated by acid catalysts to a hydroxyl group of hemiacetal to produce a better leaving group (4). Because $\mathrm{OH}_{2}$ group is a good leaving group, The bond distance $\mathrm{C} 7-\mathrm{O} 14$ changed from 1.38 to $2.78 \AA$, the water release produces $\mathbf{5}$. Compound $\mathbf{5}^{\prime}$ is the resonance structure of compound $\mathbf{5}$. Both $\mathbf{5}$ and $\mathbf{5}$ ' has a similar $\mathrm{C} 7-\mathrm{O} 8$ bond distance that is $1.26 \AA$. Besides that, either compound $\mathbf{5}$ or $\mathbf{5}^{\prime}$ has the similar energy that is around $433 \mathrm{~kJ} / \mathrm{mol}$. This is also proof that compound $\mathbf{5}$ and $\mathbf{5}$ ' have a resonance structure.
To give space for the second methanol attack the resonance structure 5, the bond angle of $\mathrm{H} 13-\mathrm{C} 7-\mathrm{C} 3$ detected in $119.9^{\circ}$, whereas the torsion angle $\mathrm{H} 13-\mathrm{C} 7-\mathrm{O} 8-\mathrm{C} 3$ is $179.9^{\circ}$.

Reaction mechanism continued by attacking the second methanol to the resonance structure (5 or $\left.\mathbf{5}^{\prime}\right)$ and gave intermediate 6 . Bond distance $\mathrm{C} 7-\mathrm{O} 8$ becomes further from 1.26 to $1.35 \AA$ because there is an influence of $\mathrm{O} 14$ neighbour atom, which has bonded with a $\mathrm{C} 7$ atom, whereas bond distance C7-O14 is $1.48 \AA$. The last process is deprotonation of compound 6 to gave acetal product 7. Bond distance C7-O13 and C7-O19 is similar around $1.39 \AA$, whereas C7-H18 bond distance is $1.08 \AA$. The formation energy of acetals was decreased sharply from 392.73 to $-17.43 \mathrm{~kJ} / \mathrm{mol}$ because acetal 7 is more stable than compound $\mathbf{6}$ based on its molecule energy.

Fig. 2 demonstrates the energy profile during the reaction to produce acetal product including hemiacetal, substrate and other intermediates compounds. Every point in the energy level diagram has the different molecules compared to the total energy because it has the same number of molecules. As a result, acetal product $(-17.43 \mathrm{~kJ} / \mathrm{mol})$ showed the lowest energy compared to 2-methoxybenzaldehyde $(0 \mathrm{~kJ} / \mathrm{mol})$ and a labile hemiacetal $(448.33 \mathrm{~kJ} / \mathrm{mol})$ due to its stability, acetal product and benzaldehyde substrate more stable because it's a neutral molecule and also has the symmetries bond (C7-O13 and C7-O19).

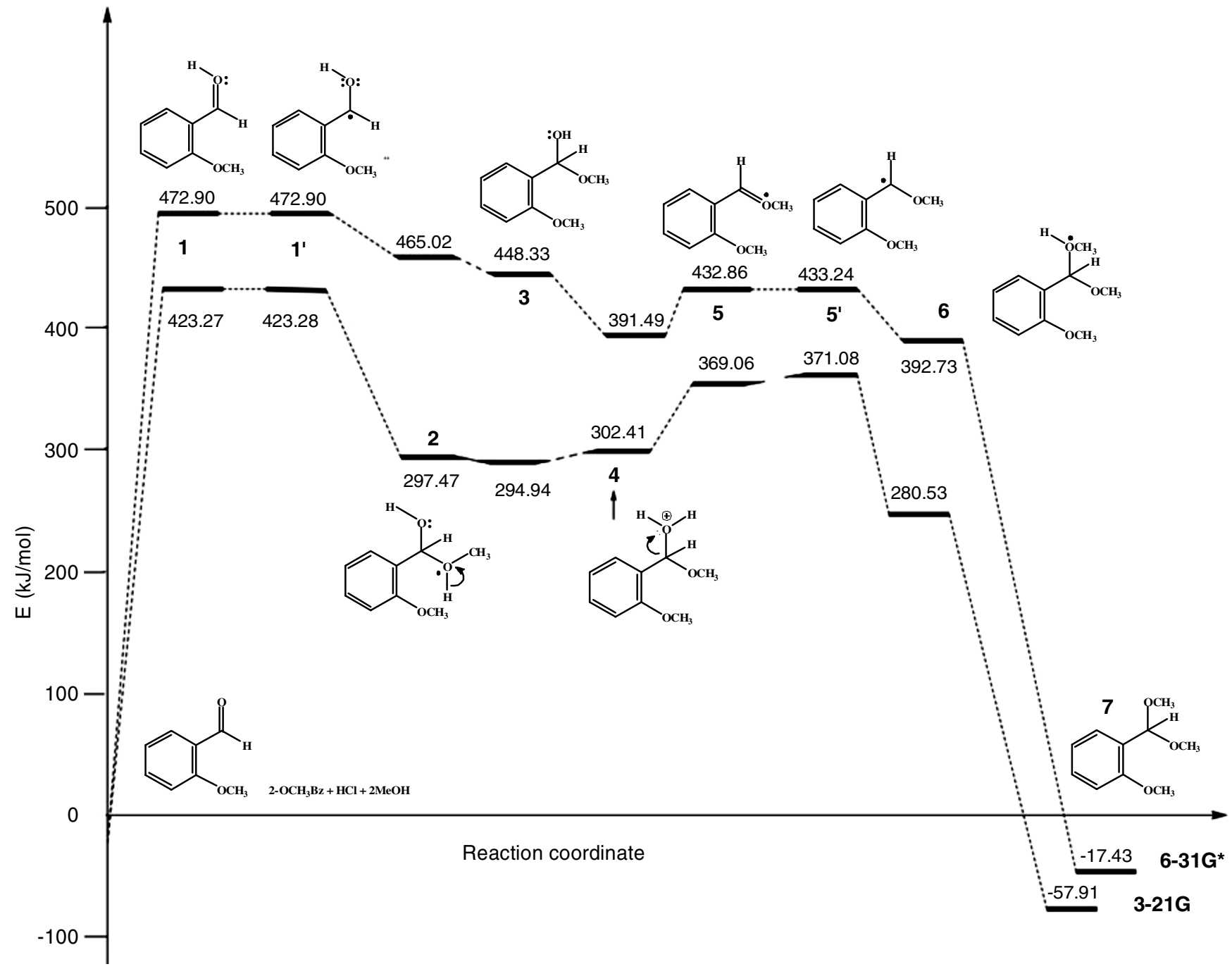

Fig. 2. Complete energy profiles for acetalization of 2-methoxybenzaldehyde 
Along reaction mechanism occurs with using 6-31G* basis sets, acetal product has the lowest energy compared to other intermediate compounds with the order was $\mathbf{7}<\mathbf{0}<\mathbf{4}<\mathbf{6}<\mathbf{5}$ and $\mathbf{5}^{\prime}<\mathbf{3}<\mathbf{2}<\mathbf{1}$ and $\mathbf{1}^{\prime}$. Resonance structure ( $\mathbf{1}$ and $\mathbf{1}^{\prime}$ ) showed higher energy compared to the other molecule due to its instability. $\mathrm{C} 7$ atom in the compound $\mathbf{1}$ ' only has three bonds so that makes it unstable and influence formation energy $\mathbf{1}^{\prime}$. Besides that, resonance structure $\mathbf{1}$ and $\mathbf{1}$ ' are an ionic compound that has a positive charge. On the formation acetal from hemiacetal, resonance structure ( $\mathbf{5}$ and $\mathbf{5}^{\prime}$ ) also showed higher energy compared to the other molecule (compound 4, 6, 7). Despite compound $\mathbf{2}$ and $\mathbf{6}$ has a surplus charge, but $\mathrm{O}$ atom in that's molecule still has a lone pair so more stable compared to compound $\mathbf{1}$ and $\mathbf{1}$ '.

Mulliken charge of atom: Mulliken analysis is used to assign an atomic electronegativity on the 2-methoxy benzaldehyde, intermediate and acetal molecule as shown in Table- 1 . Based on Mulliken charge, the electronegativity of $\mathrm{C} 7$ atom in hemiacetal molecule 3 (0.553) highest than all molecule due to an influence of $\mathrm{O} 14$ and $\mathrm{O} 8$ neighbor atom which has a high Mulliken charge that is -0.739 and -0.651 . Furthermore, hemiacetal bonded with a methoxy group $(\mathrm{O} 8 \mathrm{CH} 3)$ and also a hydroxy group (O14-H). As a result, Mulliken charge of C7 atom in acetal molecule was lower compared to hemiacetal. Despite acetal product 7 also has $\mathrm{C} 7$ atom bonded with two $\mathrm{O}$ atom with Mulliken charge amount -0.629 (O13 and O19), but a $\mathrm{C} 7$ atom in acetal only bonded with two methoxy group.

TABLE-1

MULLIKEN CHARGE OF SOME ATOM IN COMPOUND 0-7

\begin{tabular}{ccc|ccc}
\hline Compd. & Atom & Mulliken & Compd. & Atom & Mulliken \\
\hline $\mathbf{0}$ & C7 & 0.343 & $\mathbf{4}$ & C7 & 0.431 \\
$\mathbf{1}$ & C7 & 0.307 & $\mathbf{5}$ & C7 & 0.371 \\
$\mathbf{1}^{\prime}$ & C7 & 0.307 & $\mathbf{5}^{\prime}$ & C7 & 0.378 \\
$\mathbf{2}$ & C7 & 0.404 & $\mathbf{6}$ & C7 & 0.433 \\
$\mathbf{3}$ & C7 & 0.553 & $\mathbf{7}$ & C7 & 0.475 \\
\hline
\end{tabular}

Whereas, $\mathrm{C} 7$ atom in resonance structure $\mathbf{1}$ and $\mathbf{1}$ ' have a lowest electronegativity compared to all molecule (0.307). In the molecule 1, C7 atom only bonded with three atoms to produce low Mulliken charge. Besides that, on the formation acetal from hemiacetal, $\mathrm{C} 7$ atom in the resonance structure (5 and 5') also showed low Mulliken charge compared to $\mathrm{C} 7$ atom in the other molecule $(\mathbf{4 , 6}, \mathbf{7})$. Its also because $\mathrm{C} 7$ atom in the resonance structure $\mathbf{5}$ only bonded with three atoms.

\section{Conclusion}

Computational calculation based on ab initio method has been successful to confirm the mechanism of acetalization of 2-methoxybenzaldehyde with methanol using halogen acid catalyst. According to computational calculation, 2-methoxybenzaldehyde showed the lowest energy compared to 2-methoxybenzaldehyde dimethyl acetal and a labile hemiacetal due to its stability. Because of that, a reaction pathway of acetalization of 2-methoxybenzaldehyde occured through reversible reaction. Furthermore, the acid catalyst can be applied as prospect catalysts in the acetalization of 2-methoxybenzaldehyde.

Based on the Mulliken charge calculation, the electronegativity of $\mathrm{C} 7$ atom in hemiacetal molecule highest than to all molecule due to an influence neighbor atom (O14 and O8). Whereas, the electronegativity of $\mathrm{C} 7$ atom in the resonance structure $\mathbf{1}$ and $\mathbf{1}$ ' lower compared to all molecule because $\mathrm{C} 7$ atom only bonded with three atoms so that make low Mulliken charge.

\section{ACKNOWLEDGEMENTS}

The authors thank Directorate of Higher Education, the Republic of Indonesia for financial support for this work via fundamental Grant 2016 (No. 022A/UN33.8/KU/2016), 2017 (No. 045A/UN3 3.8/LL/2017), PDUPT Grant 2018 (027/ UN33.8/LL/2018). Author would like also to thank for Universitas Negeri Medan which has given facility support for this work.

\section{CONFLICT OF INTEREST}

The authors declare that there is no conflict of interests regarding the publication of this article.

\section{REFERENCES}

1. X. Han, W. Yan, K. Chen, C.-T. Hung, L.-L. Liu, P.-H. Wu, S.-J. Huang and S.-B. Liu, Appl. Catal. A Gen., 485, 149 (2014); https://doi.org/10.1016/j.apcata.2014.08.001.

2. M. Cataldo, E. Nieddu, R. Gavagnin, F. Pinna and G. Strukul, J. Mol. Catal. Chem., 142, 305 (1999); https://doi.org/10.1016/S1381-1169(98)00299-4

3. N. Narkhede and A. Patel, RSC Adv., 4, 19294 (2014); https://doi.org/10.1039/c4ra01851f.

4. B.M. Smith and A.E. Graham, Tetrahedron Lett., 47, 9317 (2006); https://doi.org/10.1016/j.tetlet.2006.10.111.

5. Y. Mei, P.A. Bentley and J. Du, Tetrahedron Lett., 50, 4199 (2009); https://doi.org/10.1016/j.tetlet.2009.01.006.

6. S. Zhao, Y. Jia and Y.F. Song, Catal. Sci. Technol., 4, 2618 (2014); https://doi.org/10.1039/C4CY00021H.

7. F. Zhang, J. Shi, Y. Jin, Y. Fu, Y. Zhong and W. Zhu, Chem. Eng. J., 259, 183 (2015);

https://doi.org/10.1016/j.cej.2014.07.119.

8. A. Dhakshinamoorthy, M. Alvaro and H. Garcia, Adv. Synth. Catal., 352, 3022 (2010);

https://doi.org/10.1002/adsc.201000537.

9. Y. Luan, N. Zheng, Y. Qi, J. Tang and G. Wang, Catal. Sci. Technol., 4, 925 (2014); https://doi.org/10.1039/c3cy00864a.

10. Y. Jin, J. Shi, F. Zhang, Y. Zhong and W. Zhu, J. Mol. Catal. Chem., 383-384, 167 (2014); https://doi.org/10.1016/j.molcata.2013.12.005.

11. M.N. Timofeeva, V.N. Panchenko, J.W. Jun, Z. Hasan, M.M. Matrosova and S.H. Jhung, Appl. Catal. Gen., 471, 91 (2014); https://doi.org/10.1016/j.apcata.2013.11.039.

12. M.J. Climent, A. Velty and A. Corma, Green Chem., 4, 565 (2002); https://doi.org/10.1039/b207506g.

13. Y. Wang, D. Jiang and L. Dai, Catal. Commun., 9, 2475 (2008); https://doi.org/10.1016/j.catcom.2008.06.021.

14. U.S.F. Arrozi, H.W. Wijaya, A. Patah and Y. Permana, Appl. Catal. A, 506, 77 (2015); https://doi.org/10.1016/j.apcata.2015.08.028.

15. T.F. Parangi, B.N. Wani and U.V. Chudasama, Ind. Eng. Chem. Res., 52, 8969 (2013); https://doi.org/10.1021/ie400686d.

16. M. Yusuf and D.E. Sitepu, AIP Conf. Proceed., 1803, 020055 (2017); https://doi.org/10.1063/1.4973182.

17. M. Yusuf, D. Roza and A.K. Nasution, AIP Conf. Proceed., 1904, 020012 (2017); https://doi.org/10.1063/1.5011869.

18. Hypercube Inc., Florida Science and Technology Park, 1115 N.W. 4th Street, Gainesville, FL, 32601 (1997) 